\title{
The Investigation of Visual Scan Patterns to Different Types of Messages in the Flight Deck
}

\author{
Wen-Chin $\mathrm{Li}^{1}$, Jingyi Zhang ${ }^{2}$, Tam Le Minh ${ }^{3}$, Jiaqi $\mathrm{Cao}^{4}$ and Lei Wang ${ }^{2}$ \\ ${ }^{1}$ Safety and Accident Investigation Centre, Cranfield University, Bedfordshire, U.K. \\ ${ }^{2}$ Flight Technology College, Civil Aviation University of China, Tianjin, China \\ ${ }^{3}$ Thales Alenia Space Deutschland GmbH, Ditzingen, Germany \\ ${ }^{4}$ Final Assembly Department, Commercial Aircraft Corporation of China, Shanghai, China
}

\begin{abstract}
The flight deck of commercial aircraft is sophisticated and searching for the necessary information at the right time is sometimes challenging. This research investigates pilot's visual parameters while interacted with two different designs of crew alerting system by eye tracking technology. There are 24 aviation professionals that participated in this experiment including commercial pilots, private pilots and avionic engineers. Compared with traditional design, the new integrated design applied proximity compatibility principles to assist pilots in searching necessary information to deal with urgent situations. The results demonstrated that the integrated design is superior to traditional design in providing accurate instructions as determined by visual behaviors. However, the integrated design increases pilot's situation awareness by redirecting attention from current task to the most critical task with the cost of a longer total fixation duration time. Pilot's visual parameters demonstrated significant differences while interacting with PFD mainly numeric, ND mostly by symbols and EICAS with presented text messages. Therefore, flight deck design has to adopt a holistic approach as pilot's visual attentions is shifting among all types of different displays to gain situation awareness rather than focus on only one display. The design of integrated EICAS can provide detailed instructions to deal with urgent situations which induced higher cognitive loads as pilot's pupil dilation is significant bigger than interacted with traditional design. By eye tracking technology, it is applicable to design human-centered flight decks to improve safety and human performance in aviation.
\end{abstract}

Key words: Eye Scan Patterns, Flight Deck Design, Human-Computer Interaction, Situation Awareness, Visual Attention

\section{INTRODUCTION}

The modern flight deck designs focus on human-computer interactions (HCI) studies as they are central to the operating and functioning of the whole system. The primary flight display (PFD) contains the basic flight information on the state of the aircraft and the autopilot modes including measures of airspeed, altitude, attitude, heading and characters present in the flight mode annunciator (FMA). The navigation display (ND) acts like a 
radar gathering information on the relative position of the aircraft to the flight path, beacons, other aircrafts or waypoints. The engine indication and crew alerting system (EICAS) display shows information on the engines and displays alert messages if needed. Although the necessary information is given to the pilots, the displays also help them in the piloting and the decision-making process with messages, such as a "PULL UP" message that will appear on the PFD if the aircraft is too low on altitude. These functions are strongly related to the three levels of Endsley's (1995) model of situation awareness. The level 1 of situation awareness is the perception of the elements in the current situation, the level 2 is the comprehension of the current situation and the level 3 is the projection of the future status. The perception of the elements is necessary to the comprehension of the situation as a whole. Similarly, the correct projection of the future status can only be achieved by understanding current situations. The design of alerting messages should help operators in the understanding of the situation and the projection of the future state (Kearney et al., 2016). Pilot's mental workload is strongly correlated to their situation awareness. An excessive mental workload may lead to a poor situation awareness due to pilot's inability to process the relevant information (Ahlstrom and Friedman-Berg, 2006). It has been argued on previous research that increasing the volume of information, even when it is accurate and task relevant, is not necessarily beneficial to the quality of decision-making. Moreover, it may even be detrimental to SA and trust among team members due to high mental demand (Marusich et al., 2016).

Visual attention is a precursor to initiating the cognitive process involved in attention distribution, situation awareness, and real-time decision-making (Lavine et al., 2002). The path of visual attention can reveal the cognitive process of human-computer interaction between operators and machines (Allsop and Gray, 2014; Kearney et al., 2016). How attention is related to information process for operation control in the context of task performance is a challenging measurement (Strayer, 2016). Therefore, an operator's eye movements on the displays can reveal human information processes and how the interface design impacts operator's performance (Goldberg and Kotval, 1999). Eye tracking has potential not only for pilot's training but also for flight skill analysis and evaluation (Peysakhovich, et al., 2018). The fixations are the reflections of information processing. They are defined by a stability of the gaze position. Two main characteristics are used to identify them. Either the low velocity of the gaze point or the low spatial variation. Therefore, two of the most largely used algorithms to distinguish them are velocity-based or dispersion-based (Salvucci and Goldberg, 2006). There are two thresholds to determine in order to implement the algorithm: a dispersion threshold and a duration threshold. In order to be considered as a fixation, the gaze point has to stay within the dispersion threshold for longer than the duration threshold. Goldberg and Kotval (1999) proposed that the minimum duration of a fixation to be considered is $100 \mathrm{~ms}$. Although Kilingaru et al. (2013) acknowledged that a fixation time of $200 \mathrm{~ms}$ is required to actually perceive information, they called the fixations below $200 \mathrm{~ms}$ as "glances", which represent brief looks with not enough time for recognition. They also distinguished the fixations with 
longer duration than $600 \mathrm{~ms}$ as "stares" which are signs of misperception. For the dispersion threshold, the areas chosen are more diverse in the literature. It is possible to use a circle with a radius of $0.5^{\circ}$ (Hoffman and Subramaniam, 1995) or $1^{\circ}$ (Liang et al., 2007). Salvucci and Goldberg (2000) described a new way to calculate the dispersion as the sum of the vertical and horizontal dispersion and recommended to use a threshold between $0.5^{\circ}$ and $1^{\circ}$, though it can also be adjusted during the data analysis.

Knowing where an individual is looking, it is possible to determine where they direct their attention. Recent research findings have provided evidence that attention can be allocated to multiple spatial positions simultaneously (Bay and Wyble, 2014). Just and Carpenter (1976) assumed that the object being fixated is the reflection of "what is at the top of the stack" of the information processing. As a consequence of this, they proposed the eye-mind assumption, stating that "there is no appreciable lag between what is being fixated and what is being processed". Although this hypothesis could be argued because objects can be perceived with the peripheral vision, Posner (1980) highlighted how the peripheral vision is used to direct the attention, thus the point of gaze, more than to simply process the information. It is noted that in a demanding operation environment, the maintenance of attention to preview for next operation task could be accompanied by withdrawal of attention for the task in hand (Jagacinski et al., 2017). Heatmap is the major application to analyse the positions of gaze and corresponding operator's attention distributions among the areas of interests (Takahashi et al., 2018). A heatmap of fixation can be created from the positions of fixation points. The hot zones with higher density designate where pilots focused their gaze with higher frequencies (Pfeiffer and Memili, 2016). Horn, Li and Braithwaite (2018) proposed that pilots distributed their attentions significantly among airspeed indicator, altitude indicator, attitude indicator and Autopilot Flight Director System (AFDS) status (figure 1) during landing phase shown by heatmap based on eye tracking technology. Previous research on flight deck design had demonstrated that the integrated human-centred design did facilitate pilot's situation awareness and reduced cognitive loads on information processing (Li et al., 2017).

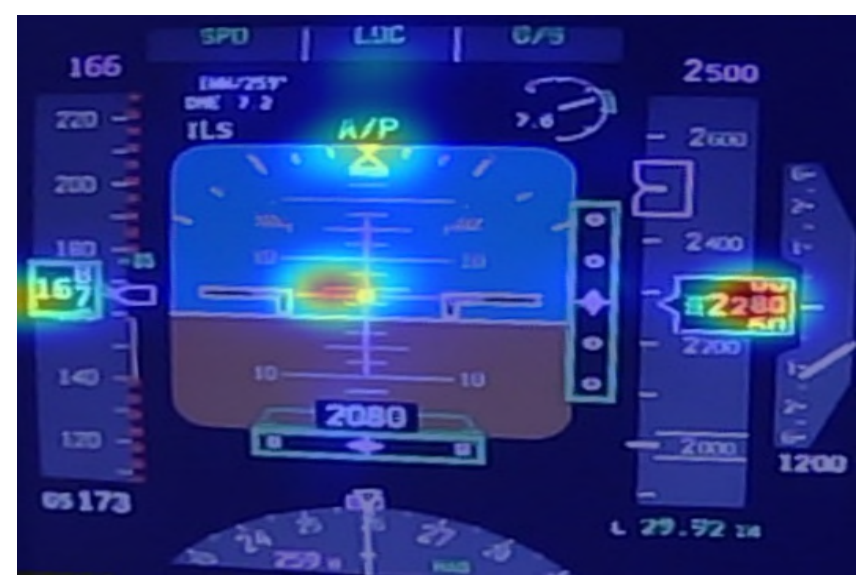

Figure 1. Pilot's visual scan patterns shown as heatmap reflected to attention distributions among Primary Flight Display (PFD) 
The task of handling emergency situations in flight deck can be simplified as a single cognitive process by identifying cues from the external environment to search for a specific solution. If a new design could reduce search space and time, crews will have more time left for solving the problems in the external world. It is possible to make representations of Quick Reference Handbook (QRH) more active in order to help crews see what is most relevant to deciding what to do next (Hollan et al., 2000). The QRH contains all the procedures applicable for abnormal and emergency conditions in an easy-to-use format and is designed with the intention of allowing flight crews to minimize the need for a lot of effortful analysis when time may be limited and workload is high (Burian, 2004). Wickens and Carswell (1995) proposed the Proximity Compatibility Principle (PCP) for information integration, which suggests that two pieces of information need to be processed together should be placed in close spatial proximity.

Pilots have to interpret the cues available to them and find the appropriate checklist to solve problems (Burian, 2006). By applying eye tracking devices to evaluate the relation between a human and a design, which contains eye movement, including gaze, fixation and saccade, is controlled by ongoing cognitive processing, so that it is possible to analyse human behaviour by examining eye movement. This assumption has been validated by many previous researchers in reading (Just and Carpenter, 1980; Rayner et al., 1989; Rayner and Pollatsek, 1992), cognitive tasks (Salvucci and Goldberg, 2000; Ahlstrom and Friedman-Berg, 2006; Stanton et al., 2017; Ryffel et al., 2018), information processing tasks (Rayner, 1998; Chi et al., 2018), scanning behaviour (Allsop and Gray, 2014; Yang et al., 2018), interface evaluation (Goldberg and Kotval, 1999; Kunze et al., 2018), human-computer interaction ( $\mathrm{Yu}$ et al., 2014), and a monitoring task on remote tower operation (Kearney et al., 2018). Pilots have to manually go through the QRH and identify the relevant checklists for the situation at hand and then act accordingly. This research is focusing on the evaluation of visual parameters on a proposed integrated EICAS design type in the flight deck. To achieve this objective, the three displays including PFD, ND and EICAS are evaluated in a holistic context for human-computer interactions in the flight deck.

\section{METHOD}

\subsection{Participants}

Twenty-four aviation professionals participated in this experiment. The collected data were gathered from human participants, therefore the research proposal was submitted to the Cranfield University Research Ethics System for ethical approval (CURES/1524/2016). As stated in the consent form filled by the participants, the data 
collected by the eye-tracker and the post-experiment interviews were confidential. Participants have the right to terminate the experiment at any time and to withdraw their provided data at any moment even after the data collection.

\subsection{Apparatus}

2.2.1 Flight simulator: The flight simulator in this experiment used the software Microsoft Flight Simulator X (FSX). The hardware was mounted on a Saitek Pro Flight Yoke with a Three-lever Throttle, although only one of the levers was used (the black one as the thrust lever). Both the flight yoke and the levers were cautiously fixed on a table to avoid any kind of incident involving excessive human inputs. The aircraft used is a Boeing 777200 LR/F from the PMDG 777-200 package. The aircraft was developed in collaboration with real-life 777 crews and maintenance teams, making its cockpit accurate and reproducing nearly all the functions of a real cockpit with a high fidelity.

2.2.2 Eye tracking device: The eye tracker used was designed by Pupil Labs. It is fixed in a plastic frame destined to be worn like glasses. Two cameras were attached including a world camera and an eye camera. The world camera was fixed on the outside part of the frame, in front of the forehead. It captured the field of view of the participant, following their head movements as the frame moved with it. Its resolution was $1280 \times 720$ pixels for a sample rate of 60 frames per second. The eye camera was fixed on the side of the frame, below the participant's right eye. It was meant to capture the participant's pupil and its movements. To detect the pupil, it was equipped with an infrared illumination and an infrared detector. There are three area of interests (AOIs) which consist of PFD, ND and EICAS in the flight deck (figure 2).

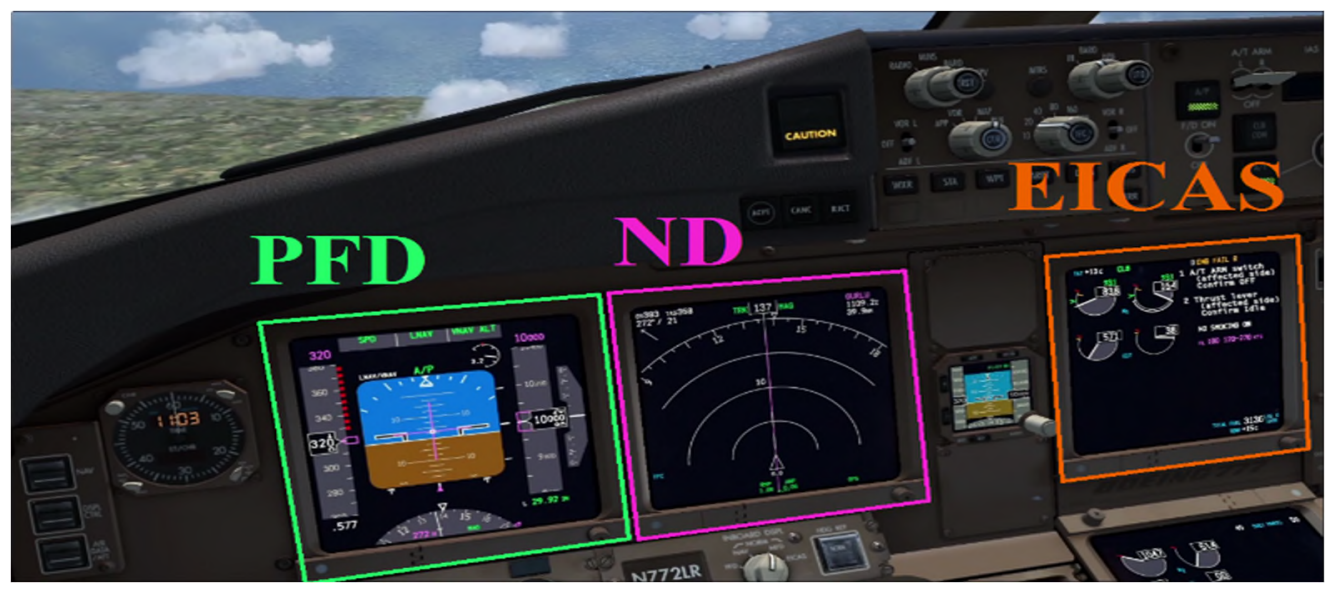

Figure 2. The analysis of visual parameters shifting among PFD, ND and EICAS on the flight deck 


\subsection{Scenario}

The aircraft had just taken-off from London Heathrow Airport climbing to 2,500ft and turning to the left according to the flight plan. Suddenly, two warning signals were presenting to the crew including an audio alert and a red master warning light. The message displayed on the EICAS is FIRE ENG L in the red colour. The single engine fire would ultimately result in a dissymmetry between the engines which grows as the scenario continues. The scenario is presented to the participants in both the traditional CAS message on the EICAS display and integrated EICAS design (figure 3). The difference between two types of EICAS design lies in that the integrated EICAS display combined CAS messages and instructions for emergent events located in QRH (Quick Reference Handbook) (on the right of figure 3). So that pilots can access to required information directly, and no further visual searching needed. While traditional EICAS shows CAS message only (on the left of figure 3) which pilots have to check QRH for corresponding procedures by searching the other display to cope with the emergencies in flight, such as engine fire procedures.

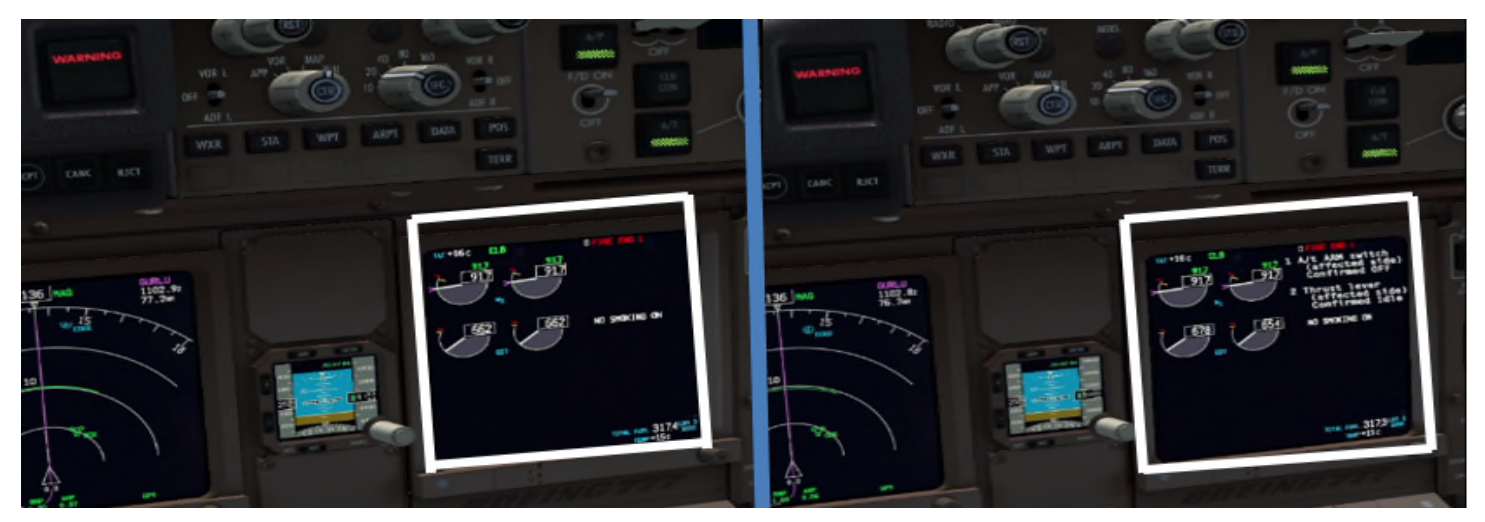

Figure 3. The traditional EICAS (left); and the "integrated" EICAS design (right)

\subsection{Research Design}

There are three interface displays (PFD, ND and EICAS) providing critical information for pilots to maintain safety of flight operations. This research had revised EICAS by combining with relevant QRH messages and kept the other two AOIs (PFD \& ND) exactly the same. The experiment took place in an isolated room with controlled illumination for the measurement of visual parameters and pupil dilation. This research started with an introduction to the experiment by "pre-briefing" and signing the participants' consent form. The participants were asked to perform two respectively flights on takingoff a Boeing 777-200 with traditional EICAS and integrated EICAS by random assignments (either A: Traditional EICAS first then Integrated EICAS or B: Integrated EICAS ten Traditional EICAS). This is to counterbalance the practice effects to participants. Participants were explained what they have to do while the scenario is developing on both traditional EICAS and integrated EICAS. They would have to monitor the PFD and the 
ND until a CAS message appeared, then they would have to read out the message presented on the CAS. The fourth step in the briefing was the adjusting of the eye-tracker device to fit the participant's eye and the calibration of the cameras. The calibration was considered acceptable if participant's fixations on the main components of the displays precisely matched the areas of interests (AOIs) for attention distributions and task performance. These components were the airspeed, the altitude and the FMA for the PFD, the aircraft symbol and the two top corners for the ND, the top message and the top left engine indicator for the EICAS. Once the scenario had been completed, a post-experiment interview would take place. They had to specify the display which is the most easy to understand the critical information from PFD, ND or EICAS on both traditional EICAS and integrated EICAS. The last step, participants were invited to fill in a demographic form to provide information about their gender, age, occupation and flight experience.

\section{RESULTS}

\subsection{Sample Characteristics}

The ages of 24 participants were from 21 to 50 years old $(\mathrm{M}=27.5, \mathrm{SD}=7.0)$, and the flight experience of participants including commercial pilots, PPL, glider pilots and helicopter pilots from 0 to 3,000 hours ( $\mathrm{M}=154.1, \mathrm{SD}=608.3)$. The eye movement measures consisted by fixation counts, fixation duration and pupil dilation among three AOIs including PFD, ND and EICAS based on two different designs (traditional design and integrated design). The assumption of sphericity was verified by using Mauchy's test, and the Bonferroni was applied to perform pairwise comparisons after a significant overall test. Effect size of factors and interactions were quantified by partial eta square ( $\eta$ 2). The descriptive of sample characteristics were shown as Table 1.

Table 1. Participants' means and standard deviations of visual parameters among three AOIs based on two different types of designs

\begin{tabular}{|c|c|c|c|c|c|c|c|c|}
\hline \multirow{2}{*}{$\begin{array}{l}\text { Visual } \\
\text { Parame- } \\
\text { ters }\end{array}$} & \multirow[b]{2}{*}{ Designs } & \multirow[b]{2}{*}{$\mathrm{N}$} & \multicolumn{2}{|l|}{ PFD } & \multicolumn{2}{|l|}{ ND } & \multicolumn{2}{|c|}{ EICAS } \\
\hline & & & $M$ & $S D$ & $M$ & $S D$ & $M$ & $S D$ \\
\hline \multirow{2}{*}{$\begin{array}{l}\text { Fixation } \\
\text { counts }\end{array}$} & $\begin{array}{l}\text { Traditional } \\
\text { EICAS }\end{array}$ & 24 & 19.04 & 7.71 & 7.62 & 6.66 & 3.33 & 3.00 \\
\hline & $\begin{array}{l}\text { Integrated } \\
\text { EICAS }\end{array}$ & 24 & 5.79 & 5.99 & 1.67 & 2.30 & 21.25 & 7.24 \\
\hline \multirow{2}{*}{$\begin{array}{l}\text { Fixation } \\
\text { duration }\end{array}$} & $\begin{array}{l}\text { Traditional } \\
\text { EICAS }\end{array}$ & 24 & 0.47 & 0.19 & 0.42 & 0.30 & 0.22 & 0.15 \\
\hline & $\begin{array}{l}\text { Integrated } \\
\text { EICAS }\end{array}$ & 24 & 0.44 & 0.41 & 0.17 & 0.33 & 0.51 & 0.24 \\
\hline \multirow{2}{*}{$\begin{array}{l}\text { Pupil } \\
\text { dilation }\end{array}$} & $\begin{array}{l}\text { Traditional } \\
\text { EICAS }\end{array}$ & 24 & 81.73 & 14.18 & 73.63 & 31.36 & 64.19 & 40.53 \\
\hline & $\begin{array}{l}\text { Integrated } \\
\text { EICAS }\end{array}$ & 24 & 76.68 & 27.78 & 41.38 & 43.65 & 86.87 & 15.71 \\
\hline
\end{tabular}




\subsection{Fixation Counts}

A repeated measure two-way ANOVA with AOIs (PFD, ND and EICAS) and designs (traditional design vs integrated design) as independent variables and fixation counts as dependent variable was conducted. There is a significant main effect of AOIs, F $(2,46)=$ $18.789, \mathrm{p}<0.001, \eta \mathrm{p} 2=0.450$, but main effect of designs is insignificant, $\mathrm{F}(1,23)=$ $0.520, p=0.478, \eta p 2=0.022$. Post-hoc pairwise comparisons on AOI showed that the fixation counts on ND are significantly less than on PFD $(\mathrm{p}<0.001)$ and EICAS $(\mathrm{p}<$ 0.001 ) (table $1 \&$ figure 4 ). The results demonstrated that participants exhibited the lowest fixation numbers on EICAS ( $\mathrm{M}=3.33, \mathrm{SD}=3.00)$, with $\mathrm{ND}(\mathrm{M}=7.62, \mathrm{SD}=6.66)$ following, and the highest fixation numbers on PFD (19.04) on traditional design; however, EICAS (21.25) has the highest fixation numbers, followed by PFD (5.79) and ND (1.67) respectively on integrated design. There is a significant interaction between AOIs and types of design on the fixation counts, $\mathrm{F}(2,46)=112.976, \mathrm{p}<0.05, \eta \mathrm{p} 2=0.831$. Participants' fixation counts are declined significantly on both PFD and ND but EICAS increased dramatically while interacted with integrated design (figure 4).

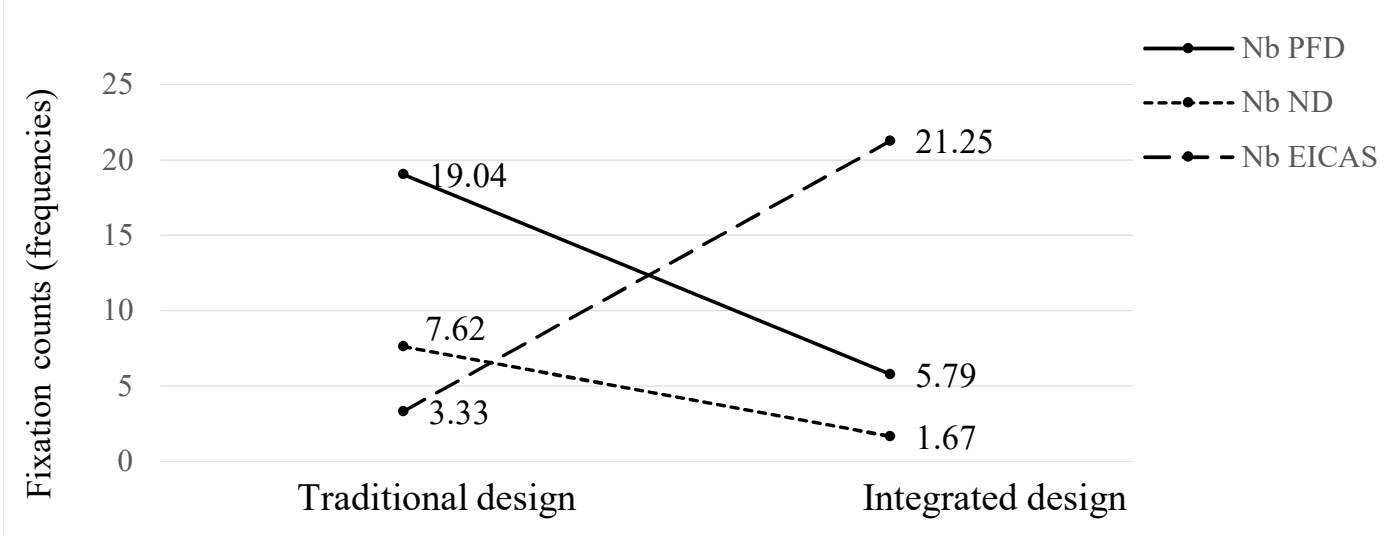

Figure. 4. The differences of fixation counts between integrated design and traditional design among three displays in the flight deck

\subsection{Fixation Duration}

There is no significant main effect on AOIs, $F(1.664,38.273)=3.117, p=0.064, \eta p 2=$ 0.119 , and no significant main effect on designs was found, $F(1,23)=0.016, p=0.901$, $\eta \mathrm{p} 2=0.001$. There is a significant interaction between AOIs (PFD, ND and EICAS) and types of design (traditional design vs integrated design) on the fixation duration, $\mathrm{F}(2,46)$ $=12.940, \mathrm{p}<0.05, \eta \mathrm{p} 2=0.360$. Examining simple effect on AOIs and designs, further post-hoc pairwise comparisons on AOIs showed that participant's fixation duration on EICAS $(0.22 \mathrm{~s})$ is significantly shorter than on ND $(0.42 \mathrm{~s})$ and PFD $(0.47 \mathrm{~s})$ on traditional design, however, fixation duration on EICAS $(0.51 \mathrm{~s})$ is significantly longer than ND $(0.17 \mathrm{~s})$ on integrated design (table $1 \&$ figure 5$)$. 


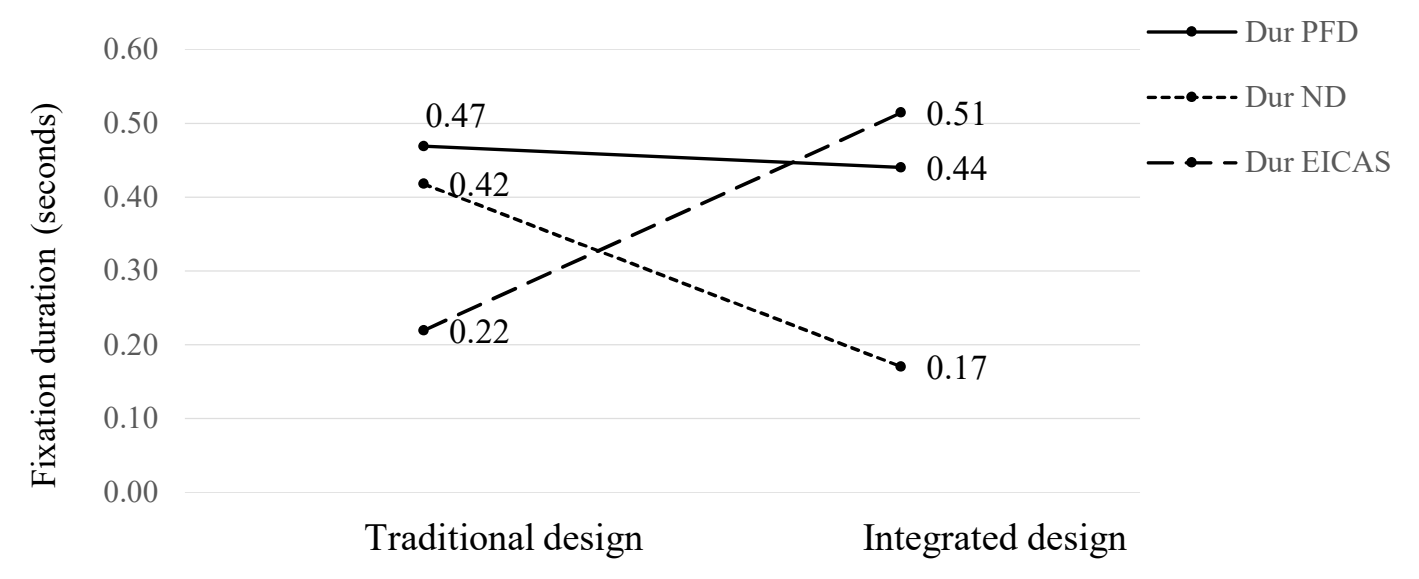

Figure 5. The differences of fixation duration between integrated design and traditional design among three displays in the flight deck

\subsection{Pupil Dilation}

A significant main effect of AOIs was found, $F(2,46)=7.813, p<0.05, \eta p 2=0.254$, but no significant main effect on designs, $\mathrm{F}(1,23)=0.884, \mathrm{P}=0.357>0.05, \eta p 2=0.037$. Post-hoc pairwise comparison on AOIs revealed participants' pupil size while monitoring ND is significantly smaller than on PFD $(p<0.01)$ and EICAS $(p<0.01)$. There is a significant interaction between AOIs (PFD, ND and EICAS) and types of design (traditional design vs integrated design), $\mathrm{F}(1.613,37.092)=14.874, \mathrm{p}<0.05, \eta \mathrm{p} 2=0.393$. Participants' pupil dilations are dramatically decreased on ND $(p<0.01)$ by interacted with integrated design compared with traditional design, therefore, pupil dilation on ND (41.38 pixels) is significantly smaller than PFD (76.68 pixels) and EICAS (86.87 pixels) in integrated design (table $1 \&$ figure 6).

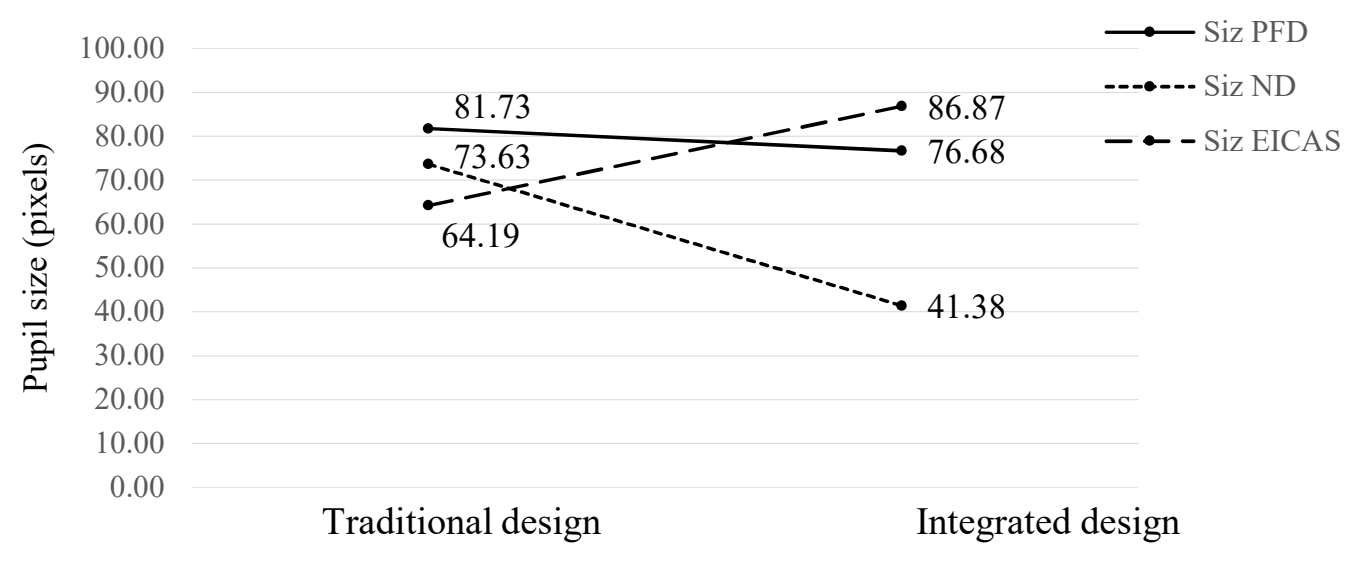

Figure 6 . The differences of pupil dilation between integrated design and traditional design among three displays in the flight deck 


\section{DISCUSSION}

The visual behaviours did reflect that the integrated design of EICAS containing operational procedures and Quick Reference Handbook could impact on the participants' cognitive workload, attention distribution and situation awareness as more operational information processing required more complicated cognitive effort. The results demonstrated that participants' eye movement parameters (fixation counts, fixation duration, \& pupil dilation) had significant interactions effects between three AOIs (figure 7) and two different types of design (figure 3). Previous research has found that the integrated design is significantly quicker than traditional design on both identifying the solutions and task completion time (Li et al., 2017). The present research further explored visual scan patterns and attention distribution of human operators in two different interface designs in order to provide a basis for human-centred design in the flight deck.

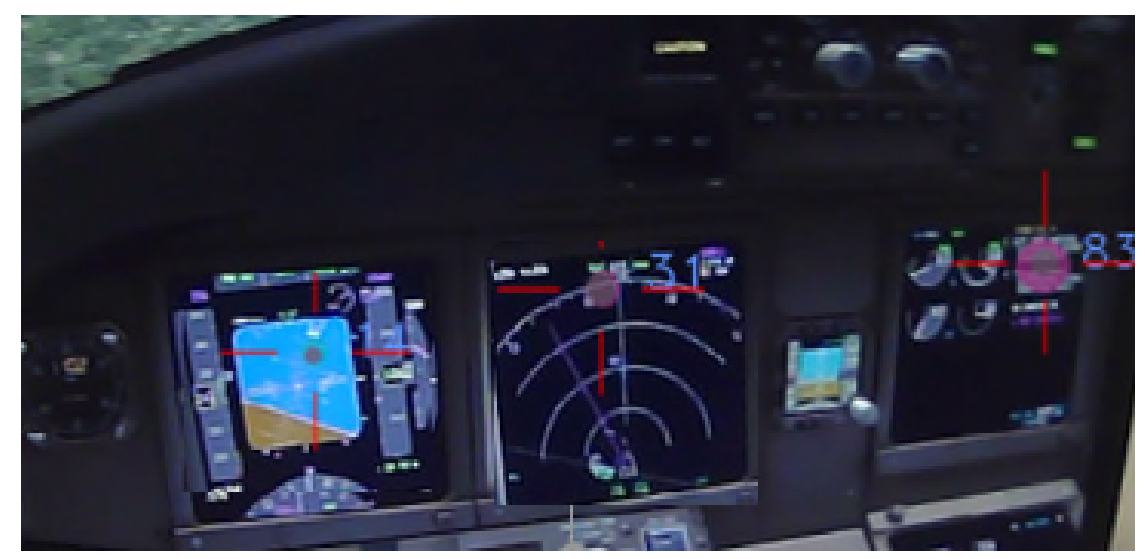

Figure 7. The fixations shifting among PFD, ND and EICAS represented attention distributions in the flight deck

\subsection{Fixation Counts and Fixation Duration Reflected to Attention Shifts in the Flight Deck}

Fixation numbers and fixation duration are closely linked to each other and are related to cognitive process and human performance (Li et al., 2016). Furthermore, the distribution of fixations and fixation duration on relevant AOIs can be an effective indicator of pilot's expertise level, also closely related to a pilot's situational awareness (Yu et al., 2014). Based on the visual parameters of this research, there are significant differences in participants' fixation counts and fixation duration between traditional EICAS design and integrated EICAS design consistently on PFD, ND and EICAS (Table 1). The fixation count is the number of fixations, which indicates the importance of AOIs; the length of fixation duration is the time fixated on an AOI, which can reflect the level of importance or difficulty in decoding information (Kotval and Goldberg, 1998). Due to the design of integrated EICAS display combined CAS messages and instructions for emergent events located in QRH together, pilots have to obtain more information from EICAS, increasing the frequency and fixated time of monitoring EICAS. Therefore, EICAS becomes even 
more important in the integrated design, so that the fixation counts and fixation duration on it had dramatically increased, which supports the phenomenon of longer fixation focused on certain locations might indicate that the information coming from those AOIs is critical to the operations and in need of more attention. However, with individuals' limited capability of attention resources, the detailed information on integrated EICAS required more cognitive processing also increased participants' fixation counts (more frequent of observations) and fixation duration (longer time to understanding the extra information). Therefore, the measurement of attention shifts must cover the interfaces in the flight deck, as the visual attentions will be reallocated among three AOIs in the flight operations. This is the reason both PFD and ND have significantly reduced fixation counts (figure 4) and fixation duration (figure 5) from traditional design to integrated design. The other explanation might be the different on the flight experiences among participants between professional commercial pilots and novice general aviation pilots. In addition, accomplishing a task at the desired level of performance requires a minimum amount of cognitive and attention resources. If attention on a task is reduced below the minimum requirement, there will be a noticeable decrease on task performance (Johnson et al., 2016).

\subsection{Integrated Design Contained More Information Required More Mental Demands}

Pupil size is influenced by illumination and also by the difficulty and complexity of tasks in hand and the pilot's cognitive workload (Gabay et al., 2011). Moreover, pupil dilation is an important indicator to understand an operator's visual attention and workload (Kowler, 2011; Sibley et al., 2011). The measurement of pupil dilation has been used to investigate the status of cognitive processes and mental workload, and pupil diameter increasing is an indication of cognitive demand (Ahlstrom and Friedman-Berg, 2006). Based on the results of statistical analysis in this research, EICAS demonstrated a significant increase and apparently largest pupil dilation (86.87 pixels) among three different AOIs in the integrated design, which indicates that participants have paid more attention while interacting with integrated EICAS. This finding could support the viewpoint proposed by Iqbal et al. (2005) that an increase in pupil size is correlated with an increase in mental workload. However, workload usually has negative impacts on the effectiveness of visual attention (Beatty, 1982; Lipshitz et al., 2001). The role of PFD and ND are the same between traditional and integrated design, participants had to find the instructions on a tablet-based QRH on the traditional design. The types of information presented on the ND mainly are symbols, and on PFD primarily numbers (airspeed \& altitudes). However, the integrated EICAS consists both of symbols of engine indications and checklist instructions that are displayed predominantly text instructions, which could be very possible to lead to decrement attention (Kircher and Ahlstrom, 2017). In the flight deck, the more information or data that is made available to pilots to improve their situation awareness, the more mental effort will be required to process all that information (Ahlstrom and Friedman-Berg, 2006). The different types of information presented in PFD, ND and EICAS might be the reason of the significant differences on pupil dilation, fixation counts and fixation duration among AOIs in the flight deck. 


\subsection{Integrated Design Facilitating Pilot's Situation Awareness?}

Human beings usually retain fixations on objects to acquire essential information to support the task at hand (Salvucci and Goldberg, 2000). The percentage of fixations on the relevant AOI is deemed as a predictor of the overall situation awareness performance (Koen et al., 2012). In this research, it is obviously that the design of integrated EICAS could improve participants' situational awareness by not only presenting CAS message (perception of the alert, level-1 of SA), but also providing instructions to deal with unexpected situations (understanding current situation, level-2 of SA). Therefore, pilots have more time to conduct the cognitive processes on decision-making and problem-solving (projection of future status, level-3 of SA), and develop more effective resolutions to critical events by rapid returning their fixations back to EICAS which demonstrated $74.01 \%$ of fixation counts and $79.28 \%$ of total fixation duration on integrated design (table 2). The total fixation time in each AOI is logically correlated to the fixation duration and the number of fixations in PFD, ND and EICAS, because it is confounding both fixation counts and fixation duration. The aggregation of fixations over time is known as the attention map or heatmap which indicates the total amount of time spent to process the information in one AOI during a chosen period (figure 8). A good approach would be to always use heatmap as complementary data to the number of fixations and the fixation duration and never alone, because a variation of fixation time could infer a change in either the fixation duration, the number of fixations or both (Jacob and Karn, 2003; Marusich, et al., 2016).

Table 2. Percentage of fixation counts and fixation duration among three AOIs between traditional design and integrated design

\begin{tabular}{|l|l|l|l|l|}
\hline & \multicolumn{1}{|c|}{ Designs } & PFD & ND & EICAS \\
\hline \multirow{2}{*}{$\begin{array}{l}\text { Percentage of total fixation } \\
\text { counts (\%) }\end{array}$} & $\begin{array}{l}\text { Traditional } \\
\text { Design }\end{array}$ & 63.48 & 25.41 & 11.11 \\
\cline { 2 - 5 } & $\begin{array}{l}\text { Integrated } \\
\text { Design }\end{array}$ & 20.17 & 5.82 & 74.01 \\
\hline \multirow{2}{*}{$\begin{array}{l}\text { Percentage of total fixation } \\
\text { duration (\%) }\end{array}$} & $\begin{array}{l}\text { Traditional } \\
\text { Design }\end{array}$ & 69.47 & 24.84 & 5.69 \\
\cline { 2 - 5 } & $\begin{array}{l}\text { Integrated } \\
\text { Design }\end{array}$ & 18.64 & 2.08 & 79.28 \\
\hline
\end{tabular}
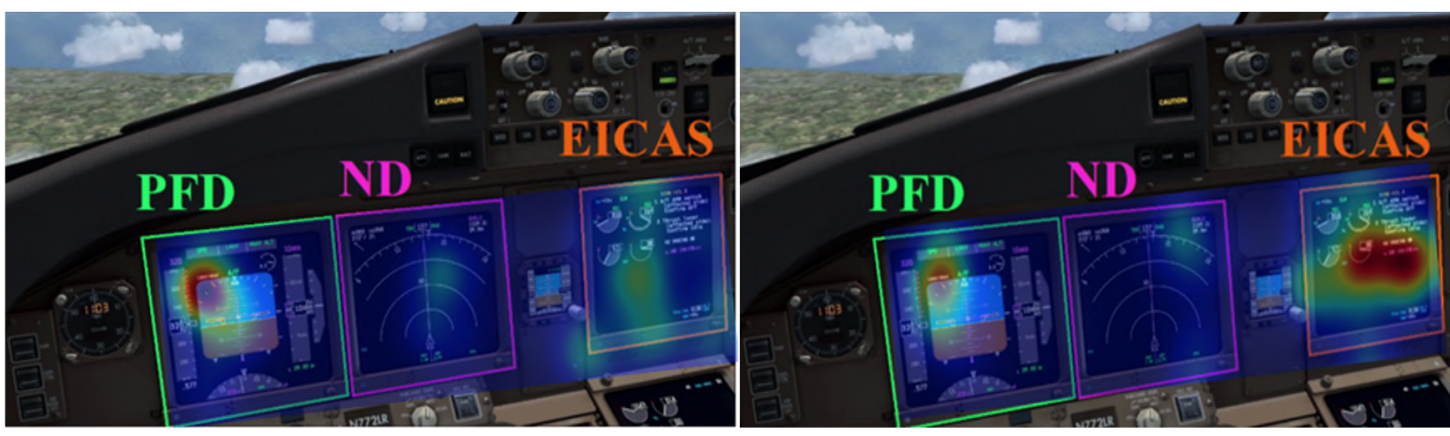
Figure 8. The heatmap represents total fixations time among PFD, ND and EICAS between traditional design (left) and integrated design (right)

In circumstances of time-limited situation, the faster the cognitive processing of the task the better the performance and the faster the processing is completed, the more time is available for subsequent tasks (Salthouse, 1992). On the other hand, longer average fixation duration might be an index of cognitive capture or over-concentration on a specific indicator, which will slow down attention shifts to the dynamic situation (Johnson and Proctor, 2004). There is a close connection between fixation duration and amount of information processing (Rayner, 1998; Singh and Singh, 2012). Short fixation durations primarily indicate operators encoding an element into working memory, and a longer fixation is more likely to signal deeper processing (Ballard et al., 1997). The integrated design demonstrated that the fixation duration on EICAS is significantly longer than PFD and ND. It can be explained that integrated EICAS is a good human-centered design to facilitate flight crews searching required information to deal with urgent situation by combined CAS messages and QRH instructions. It can facilitate the information processing by leaving out level-1 and level-2 of situation awareness, and thus, improving pilot's inflight decision-making. This integrated EICAS is adopted Proximity Compatibility Principle (Wickens and Carswell, 1995) by combined different automated systems to cluster information together, as the EICAS display facilitated pilots responding to critical situations properly.

\section{CONCLUSION}

This research analyzes pilot's visual parameters while interacted with flight deck displays to investigate cognitive processing related to human-computer interaction. The most critical issues in an eye-tracking study are the choice of the metrics and experimental design. The fixation numbers and fixation duration demonstrated significant differences on total fixation time among PFD, ND and EICAS between traditional and integrated designs. Fixation numbers will increase if the pilot need several fixations to understand the message. However, this metric is very task dependent as the pilot fixates logically the areas that are more important for the specific task the pilot was asked to complete. The system developers of future flight deck have to be aware that the amount of text should be minimal on the displays due to cognitive processing and time consuming. This is why the PFD and the ND are essentially consisting in symbols and numbers. However, all the information cannot be converted into numbers or symbols. The numbers and symbols can only carry a limited amount of specific information, therefore, the contents of CAS messages and checklist instructions cannot always be presented as symbols on EICAS. Integrated design applied the Proximity Compatibility Principle to assist pilots searching necessary information and understanding critical situations to develop suitable solutions. The proposed integrated design expanded to traditional design by providing accurate instructions to deal with emergent situations. Based on the analysis of pilot's visual behaviors and attention distributions, there is a prospective application of eye tracking for future flight 
design. Fixation counts and duration can be used to determine whether flight crews notice an emergency CAS message by examining if a fixation has been made on EICAS display. In addition, continuously monitoring the trajectories of fixations can assist pilots to track interested objects in operational environments, provide directional instructions (i.e. by Head-Up Display) to direct pilot to see the information which is critical to safety of flight operations. The integrated design can increase pilot's situation awareness by redirecting pilot's attention from current task-in-hand to the most critical task to eliminate the effects of startle and tunneling vision by providing easy access to instructions that can help to deal with the problems. Overall, integrated design (task based) has a better potential in improving crew performance during emergent situations. This research provides a preliminary overview on the effectiveness of such integration of CAS and QRH to increase pilot's situation awareness.

\section{REFERENCE}

Ahlstrom, U., \& Friedman-Berg, F. J. (2006). Using eye movement activity as a correlate of cognitive workload. International Journal of Industrial Ergonomics, 36(7), 623636. https://doi.org/10.1016/j.ergon.2006.04.002

Allsop, J., \& Gray, R. (2014). Flying under pressure: Effects of anxiety on attention and gaze behavior in aviation. Journal of Applied Research in Memory and Cognition, 3(2), 63-71. https://doi.org/10.1016/j.jarmac.2014.04.010

Ballard, D. H., Hayhoe, M. M., Pook, P. K., \& Rao, R. P. N. (1997). Deictic codes for the embodiment of cognition. Behavioral and Brain Sciences, 20(4), 723-742. https://doi.org/10.1017/S0140525X97001611

Bay, M., \& Wyble, B. (2014). The benefit of attention is not diminished when distributed over two simultaneous cues. Attention Perception and Psychophysics, 76(5), 1287-1297. https://doi.org/10.3758/s13414-014-0645-z

Beatty, J. (1982). Task-evoked pupillary responses, processing load, and the structure of processing resources. Psychological bulletin, 91(2), 276.

Burian, B. K. (2004). Emergency and abnormal checklist design factors influencing flight crew response: A case study. Paper presented at the Proceedings of the International Conference on Human-Computer Interaction in Aeronautics 2004.

Burian, B. K. (2006). Aeronautical emergency and abnormal checklists: expectations and realities. Paper presented at the Proceedings of the Human Factors and Ergonomics Society Annual Meeting. https://doi.org/10.1177/154193120605000122

Endsley, M. R. (1995). Measurement of Situation Awareness in Dynamic Systems. Human Factors, 37(37), 65--84. https://doi.org/10.1518/001872095779049499

Gabay, S., Pertzov, Y., \& Henik, A. (2011). Orienting of attention, pupil size, and the norepinephrine system. Attention Perception and Psychophysics, 73(1), 123-129. https://doi.org/10.3758/s13414-010-0015-4

Chi, C.-F., Cheng, C.-C., Shih, Y.-C., Sun, I. S., \& Chang, T.-C. (2018). Learning rate and subjective mental workload in five truck driving tasks. Ergonomics, 1-15. https://doi.org/10.1080/00140139.2018.1545054

Goldberg, J. H., \& Kotval, X. P. (1999). Computer interface evaluation using eye movements: methods and constructs. International Journal of Industrial Ergonomics, 24(6), 631-645. https://doi.org/10.1016/S0169-8141(98)00068-7

Hoffman, J. E., \& Subramaniam, B. (1995). The role of visual-attention in saccade eye- 
movements. Perception and Psychophysics, 57(6), 787-795. https://doi.org/10.3758/bf03206794

Hollan, J., Hutchins, E., \& Kirsh, D. (2000). Distributed cognition: Toward a new foundation for human-computer interaction research. ACM Transactions on ComputerHuman Interaction (TOCHI), 7(2), 174-196. https://doi.org/10.1145/353485.353487

Horn, A., Li, W. C., \& Braithwaite, G. (2018). Human-Centered Design of Flight Mode Annunciation for Instantaneous Mode Awareness. In International Conference on Engineering Psychology and Cognitive Ergonomics (pp. 137-146). Springer, Cham. https://doi.org/10.1007/978-3-319-91122-9_12

Iqbal, S. T., Adamczyk, P. D., Zheng, X. S., \& Bailey, B. P. (2005). Towards an index of opportunity:understanding changes in mental workload during task execution. Paper presented at the Sigchi Conference on Human Factors in Computing Systems. https://doi.org/10.1145/1054972.1055016

Jacob, R. J. K., \& Karn, K. S. (2003). Commentary on Section 4 - Eye Tracking in HumanComputer Interaction and Usability Research : Ready to Deliver the Promises. Minds Eye, 2(3), 573-605. https://doi.org/10.1016/B978-044451020-4/50031-1

Jagacinski, R. J. , Hammond, G. M. , \& Rizzi, E. . (2017). Measuring memory and attention to preview in motion. Human Factors, 59(5):796-810. https://doi.org/10.1177/0018720817695193.

Johnson, A., \& Proctor, R. W. (2004). Attention: Theory and Practice. London: Sage Publications, Inc. https://doi.org/10.4135/9781483328768

Johnson, A. W. , Duda, K. R. , Sheridan, T. B. , \& Oman, C. M. . (2016). A closed-loop model of operator visual attention, situation awareness, and performance across automation mode transitions. Human Factors, 59(2), 229. https://doi.org/10.1177/0018720816665759

Just, M. A., \& Carpenter, P. A. (1976). Eye fixations and cognitive processes. Cognitive Psychology, 8(4), 441-480. https://doi.org/10.1016/0010-0285(76)90015-3

Just, M. A., \& Carpenter, P. A. (1980). A theory of reading: From eye fixations to comprehension. Psychological review, 87(4), 329. https://doi.org/10.1037/0033295X.87.4.329

Kearney, P., Li, W. C., Braithwaite, G. R., \& Lin, J. J. H. (2018). How much is too much on monitoring tasks? Visual scan patterns of single air traffic controller performing multiple remote tower operations. International Journal of Industrial Ergonomics, 67 (September 2018). https://doi.org/10.1016/j.ergon.2018.05.005

Kearney, P., Li, W.-C., Braithwaite, G., \& Greaves, M. (2017). The Investigation HumanComputer Interaction on Multiple Remote Tower Operations. Paper presented at the 2017 International Conference on Human Computer Interaction, Vancouver, Canada. https://doi.org/10.1007/978-3-319-58472-0_23

Kearney, P., Li, W. C., \& Lin, J. J. H. (2016). The impact of alerting design on air traffic controllers' response to conflict detection and resolution. International Journal of Industrial Ergonomics, 56, 51-58. https://doi.org/10.1016/j.ergon.2016.09.002

Kilingaru, K., Tweedale, J. W., Thatcher, S., \& Jain, L. C. (2013). Monitoring pilot "Situation Awareness". Journal of Intelligent and Fuzzy Systems, 24(3), 457-466. https://doi.org/10.3233/IFS-2012-0566

Kotval, X. P., \& Goldberg, J. H. (1998). Eye movements and interface component grouping: 
An evaluation method. Paper presented at the Proceedings of the Human Factors and Ergonomics Society 42nd Annual Meeting, Vols 1 and 2, Santa Monica: CA., U.S.A. https://doi.org/10.1177/154193129804200509

Kowler, E. (2011). Eye movements: The past 25 years. Vision Research, 51(13), 1457-1483. https://doi.org/10.1016/j.visres.2010.12.014

Kunze, A., Summerskill, S. J., Marshall, R., \& Filtness, A. J. (2018). Automation transparency: implications of uncertainty communication for human-automation interaction and interfaces. 1-16. https://doi.org/10.1080/00140139.2018.1547842

Lavine, R. A., Sibert, J. L., Gokturk, M., \& Dickens, B. (2002). Eye-tracking measures and human performance in a vigilance task. Aviation Space and Environmental Medicine, 73(4), 367-372. https://doi.org/10.1016/S0009-2614(01)00548-6

Lipshitz, R., Klein, G., Orasanu, J., \& Salas, E. (2010). Taking stock of naturalistic decision making. Journal of Behavioral Decision Making, 14(5), 331-352. https://doi.org/10.1002/bdm.381

Li, W. C., Yu, C. S., Braithwaite, G., \& Greaves, M. (2016). Pilots' Attention Distributions Between Chasing a Moving Target and a Stationary Target. Aerospace medicine and human performance, 87(12), 989-995. https://doi.org/10.3357/AMHP.4617.2016

Li, W. C., Cao, J., Lin, J. H., Braithwaite, G., \& Greaves, M. (2017). The Evaluation of Pilot's First Fixation and Response Time to Different Design of Alerting Messages. In International Conference on Engineering Psychology and Cognitive Ergonomics (pp. 21-31). Springer, Cham. https://doi.org/10.1007/978-3-319-58472-0_2

Liang, Y., Reyes, M. and Lee, J. (2007). Real-Time Detection of Driver Cognitive Distraction Using Support Vector Machines. IEEE Transactions on Intelligent Transportation Systems, 8, 340-350. https://doi.org/10.1109/TITS.2007.895298

Marusich, L. R. , Bakdash, J. Z. , Onal, E. , Yu, M. S. , Schaffer, J. , \& Odonovan, J. , et al. (2016). Effects of information availability on command-and-control decision making: performance, trust, and situation awareness. Human Factors, 58(2), 301-321. https://doi.org/10.1177/0018720815619515

Peysakhovich, V., Lefrançois, O., Dehais, F., \& Causse, M. (2018). The Neuroergonomics of Aircraft Cockpits: The Four Stages of Eye-Tracking Integration to Enhance Flight Safety. Safety, 4(1), 8. https://doi.org/10.3390/safety4010008

Pfeiffer, T., \& Memili, C. (2016). Model-based real-time visualization of realistic threedimensional heat maps for mobile eye tracking and eye tracking in virtual reality. Paper presented at the Biennial ACM Symposium on Eye Tracking Research and Applications.https://doi.org/10.1145/2857491.2857541

Posner, M. I. (1980). Orienting of attention. Quarterly Journal of Experimental Psychology, 32(1), 3-25. https://doi.org/10.1080/00335558008248231

Rayner, K. (1998). Eye movements in reading and information processing: 20 years of research. Psychological bulletin, 124(3), 372. https://doi.org/10.1371/journal.pone.0060752

Rayner, K., \& Pollatsek, A. (1992). Eye movements and scene perception. Canadian Journal of Psychology/Revue canadienne de psychologie, 46(3), 342. http://dx.doi.org/10.1037/h0084328

Rayner, K., Sereno, S. C., Morris, R. K., Schmauder, A. R., \& Clifton Jr, C. (1989). Eye movements and on-line language comprehension processes. Language and Cognitive 
Processes, 4(3-4), SI21-SI49. https://doi.org/10.1080/01690968908406362

Ryffel, C. P., Muehlethaler, C. M., Huber, S. M., \& Elfering, A. (2018). Eye tracking as a debriefing tool in upset prevention and recovery training (UPRT) for general aviation pilots. Ergonomics, 1-11. https://doi.org/10.1080/00140139.2018.1501093

Salthouse, T.A., 1992. Mechanisms of Age-cognition Relations in Adulthood. Psychology Press, Hillsdale, NJ.

Salvucci, D. D., \& Goldberg, J. H. (2000). Identifying Fixations and Sccades in Eye-Tracking Protocols. Palm Beach Gardens, U.S.A. https://doi.org/10.1145/355017.355028

Strayer, D. L. (2016). Attention and driving. In J. M. Fawcett, E. F. Risko, \& A. Kingstone (Eds.), The handbook of attention (pp. 423-442). Cambridge, MA: MIT Press.

Sibley, C., Coyne, J., \& Baldwin, C. (2011). Pupil Dilation as an Index of Learning. Paper presented at the Human Factors and Ergonomics Society Meeting. https://doi.org/10.1177/1071181311551049

Singh, H., \& Singh, J. (2012). Human eye tracking and related issues: A review. International Journal of Scientific and Research Publications, 2(9), 1-9. https://doi.org/10.1057/palgrave.rm.8240175

Stanton, N. A., Plant, K. L., Roberts, A. P., \& Allison, C. K. (2017). Use of Highways in the Sky and a virtual pad for landing Head Up Display symbology to enable improved helicopter pilots situation awareness and workload in degraded visual conditions. Ergonomics, 1-13. https://doi.org/10.1080/00140139.2017.1414301

Takahashi, R., Suzuki, H., Chew, J. Y., Ohtake, Y., Nagai, Y., \& Ohtomi, K. (2017). A System for Three-Dimensional Gaze Fixation Analysis Using Eye Tracking Glasses. Journal of Computational Design and Engineering. https://doi.org/10.1016/j.jcde.2017.12.007

Wickens, C. D., \& Carswell, C. M. (1995). The proximity compatibility principle: its psychological foundation and relevance to display design. Human Factors, 37(3), 473-494. https://doi.org/10.1518/001872095779049408

Wickens, C.D., \& Holland, J.G., (2000). Engineering Psychology and Human Performance, third ed. Prentice Hall, Upper Saddle River, NJ. https://doi.org/10.1146/annurev.ps.27.020176.001513

Yang, L.-D., Yu, R.-F., Lin, X.-L., Xie, Y.-Q., \& Ma, L. (2018). Visual search tasks: measurement of dynamic visual lobe and relationship with display movement velocity. Ergonomics, 61(2), 273-283. https://doi.org/10.1080/00140139.2017.1353138

Yu, C.-S., Wang, E. M.-y., Li, W.-C., \& Braithwaite, G. (2014). Pilots' visual scan patterns and situation awareness in flight operations. Aviation, space, and environmental medicine, 85(7), 708-714. https://doi.org/10.3357/ASEM.3847.2014

Yu, C.-S., Li, W. C., Wang, E. M., Braithwaite, G., \& Greaves, M. (2016). Pilots' visual scan patterns and attention distribution during the pursuit of a dynamic target. Aerospace Medicine and Human Performance, 87(1), 40-47. https://doi.org/10.3357/AMHP.4209.2016 
2019-04-28

Visual scan patterns reflect to

human-computer interactions on

processing different types of messages

in the flight deck

\section{Li, Wen-Chin}

Elsevier

Li W-C, Zhang JY, Minh T, et al., (2019) Visual scan patterns reflect to human-computer interactions on processing different types of messages in the flight deck. International Journal of Industrial Ergonomics, Volume 72, July 2019, pp. 54-60

https://doi.org/10.1016/j.ergon.2019.04.003

Downloaded from Cranfield Library Services E-Repository 